\title{
Evaluation of addition ABS and EPDM effect on the mechanical properties of ternary polymer blends
}

\author{
Sihama Issa Salih, Jawad Kadhum Oleiwi, Rawaa Adnan Abdle Ameer
}

Materials Engineering Department, University of Technology, Baghdad, Iraq

Email address:

sihama_salih@yahoo.com (S. I. Salih), jawadkad@yahoo.com (J. K. Oleiwi), eng.rawaa12@yahoo.com (R. A. A. Ameer)

\section{To cite this article:}

Sihama Essa Salih, Jawad Kadhum Oleiwi, Rawaa Adnan Abdle Ameer. Evaluation of Addition ABS and EPDM Effect on the Mechanical Properties of Ternary Polymer Blends. International Journal of Materials Science and Applications. Vol. 4, No. 1, 2015, pp. 39-46. doi: 10.11648/j.ijmsa.20150401.18

\begin{abstract}
Polymer blends are capable of providing materials with extended useful properties beyond the range that can be obtained from single polymer. Blends of polystyrene (PS) and polypropylene (PP) with adding acrylonitrile-butadiene-styrene $(\mathrm{ABS})$ or ethylene propylene diene monomer (EPDM) are prepared in different ratios by melt blending technique which was carried out using a double screw extruder. The tensile, flexural, impact and hardness tests of all the prepared samples were study. The results from this work show that the elongation property and impact properties for blend system increase with increase PP content in polymer blend of (PS:PP), also increase value of these properties with increase the ratio of adding (ABS or EPDM) for polymer blend (PS:5\%PP).The highest values of impact strength was $\left(10.68 \mathrm{Kj} / \mathrm{m}^{2}\right)$ for ternary polymers blend (90\%PS:5\%PP:5\%EPDM) and the high values of fracture toughness $(6.125 \mathrm{MPa} \sqrt{\mathrm{m}})$ for ternaty polymer blend (90\%PS:5\%PP:5\%ABS).
\end{abstract}

Keywords: Mechanical Properties, Ternary Polymer Blends, PS:PP, ABS and EPDM Effect

\section{Introduction}

Polymer blend are generated by the mixing of two or more polymers to gather in order to combine the characteristic of individual polymers. Polymer blends are wider used materials in the modern polymer industry owing to their range of properties as compared to individual polymers and ease of tailoring of properties. As a result, polymer blends find application in numerous fields such as adhesion, colloidal stability and design of composite and biocompatible materials. The dispersed phase in certain systems can also acquire a specific morphology beneficial for application like platy morphology, useful for barrier application [1].

Polymer blends or alloys have been the subject of intense study for a long time, but in the recent years, totally immiscible blends are of interest to many polymer researchers with respect to making such blends/alloys compatible. Blending is an attractive method of creating new materials with improvement and flexibility in performance, and better properties than existing polymers. The process of modifying interfacial properties of an immiscible polymer blend leading to the creation of polymer blend is called compatibilization. The achievement of the compatibilization, whether by addition of third component (compatibilizer) or by inducing in situ chemical reaction between blend components, has played a pertinent role in the development of polymer blend, typical example for immiscible polymer blends is blend of polypropylene (PP) and polystyrene (PS) which are two of the most widely used plastics in the world .PS is a brittle and amorphous polymer which belongs to the aromatic group whereas PP is a semi-crystalline and ductile polymer belongs to aliphatic group with straight carbon chains. To make both PP and PS compatible requires an intermediate substance which can bond them together while maintaining their respective properties [2].

A. A. Adewole et al., produced blends of polypropylene (PP) and polystyrene (PS) are obtained by graft copolymerization of styrene onto polypropylene chains, these blend was prepared by commercial TSE-30 extruder. The results show that both the free polystyrene and the graft copolymer, (PP-g-PS), act as nucleates for the polypropylene phase, thus increasing both the degree of crystallinity and the crystallization temperature of the blends [3].

C.Jian and D.MinJia, studied the effect of StyreneEthylene/Propylene diblock copolymer (SEP) on the morphology and mechanical properties of polypropylene/polystyrene (PP/PS) blends. These blends 
prepared by melt blending in a Bra bender PL2000 chamber at $\left(200^{\circ} \mathrm{C}\right)$ with a rotor speed of $(100 \mathrm{r} / \mathrm{min})$. The results showed that (SEP) diblock copolymer, act as a compotibilizer in (PP/PS) immiscible blends, can diminish the coalescence of the dispersed particles, reduce their average particle size, change their phase morphologies significant, and increase the mechanical properties, it was found that SEP has better compatibilization effect on the PP/PS (20/80) blend [4].

V. Wantinee et.al, studied the effect of composition and morphology on tensile Young's modulus and impact resistance for immiscible polymer blends of polystyrenepolypropylene (PS/PP) and polystyrene-high density polyethylene (PS/HDPE) were prepared by melt extrusion using a single screw extruder in the systems, this work show that the (PS/HDPE) system showed impact properties poor, whereas excellent impact resistance was noted in the (PS/PP) blends. Indeed, the (20\%) PS in PP blend possessed an impact strength that was $(127 \%)$ greater than the proportional value for this composition. The PS/PP blends appear to be first-rate engineering materials from the perspective of tensile modulus and impact resistance, especially in the range of $(15-30 \%)$ PS, also $20 \%$ PS/PP blend possesses tensile modulus that is $(38.2 \%)$ greater than neat $\mathrm{PP}$ and with an impact resistance that is $(94 \%)$ greater [5].

W.Brostow et.al, investigated effects of the presence of Styrene-ethylene/butylene-styrene (SEBS) block copolymer on the mechanical properties of polypropylene /polystyrene (PP / PS) blends, prepared by melt casting. Since the copolymer causes formation of smaller particles of the dispersed PS phase in PP matrix blends, there is improved energy transmission and dissipation resulting in higher impact strength. The SEBS additive is relatively soft and causes a decrease in stress at break but an increase in elongation at break in tensile testing [6].

A. I. Buthainaet. al., studied mechanical and the thermal Properties for blends of polystyrene (PS) and AcrylonitrileButadiene-Styrene (ABS) are prepared in different ratios by melt blending technique which was carried out using a single screw extruder. The results show that the mechanical properties for blend system are better than those of pure polymers, also the (DSC) test gives good indications of improving state of miscibility for most blend ratios; there is only one glass transition temperature between the two values of pure polymers [7].

The aim of this work is to study the effect of addition different ratio from Acrylonitrile-Butadiene-Styrene (ABS) and Ethylene propylene diene monomer (EPDM) of the optimal polymer blend (PS: $5 \% \mathrm{PP}$ ) on the some mechanical properties.

\section{Material and Experimental Procedure}

In this research four polymer materials were used polystyrene, polypropylene, Acrylonitrile-Butadiene-Styrene (ABS) and ethylene propylene diene monomer (EPDM). All polymers were supplied from the supplier in a pellet form and physical properties data for each polymer is given in Table (1).

Table (1). physical properties of polymer materials used.

\begin{tabular}{lllll}
\hline Polymer & Melt flow index $(\mathbf{g m} / \mathbf{1 0} \mathbf{~ m i n})$ & Density $\left(\mathbf{g} / \mathbf{c m}^{2}\right)$ & Elongation at break & Supplier \\
\hline PS & 2.5 & 1.05 & $3 \%$ & Sabic Company \\
PP & 11 & 0.908 & $100 \%$ & Sabic Company \\
ABS & 26 & 1.05 & $5-25 \%$ & Basf Company \\
EPDM & - & $1.4 \mathrm{~g} / \mathrm{cm}^{3}$ & 100 to $300 \%$ & Basf Company \\
\hline
\end{tabular}

\section{Blending}

Polymer blends were mixed according to the ratios displayed in Table (2) and subsequent melt processed in double screw extruder machine. The blending temperature profiles on the extruder for three zones from the feeding, compression and metering die zone are $195{ }^{\circ} \mathrm{C}, 200{ }^{\circ} \mathrm{C}$ and $200{ }^{\circ} \mathrm{C}$ respectively, the extrusion speed was $(50 \mathrm{rpm})$ to form a long plate of polymer blends (almost $4 \mathrm{~mm}$ thickness and $60 \mathrm{~mm}$ width).

Table (2). Blends composition.

\begin{tabular}{|c|c|c|c|c|c|c|}
\hline \multirow{2}{*}{ Polymer systems } & \multirow{2}{*}{\multicolumn{2}{|c|}{ Ratio of mixing }} & & \multicolumn{3}{|c|}{ Temperature $\left({ }^{\circ} \mathrm{C}\right)$} \\
\hline & & & & Zone1 & Zone2 & Zone 3 \\
\hline PS:PP & $95: 5$ & $90: 10$ & $85: 15$ & 195 & 200 & 200 \\
\hline PS:5\%PP:ABS & $94: 5: 1$ & $92: 5: 3$ & $90: 5: 5$ & 195 & 200 & 200 \\
\hline PS:5\%PP:EPDM & $94: 5: 1$ & $92: 5: 3$ & $90: 5: 5$ & 195 & 200 & 200 \\
\hline
\end{tabular}

\section{Mechanical Tests}

Samples were prepared for the tensile test in accordance with ASTM D638 [8] with computerized universal testing machine model (WDW-50E). The test was conducted at a constant strain rate of the order $5 \mathrm{~mm} / \mathrm{min}$ at room temperature. Tensile stress was applied till the failure of the sample and stress -strain curve was obtained, each sample was tested for 3 times and average results have been reported at room temperature.

The flexural modulus measured by three point tests, this test is performed according to ASTM D790 each sample was tested for 3 times and average results have been reported at room temperature [9]. 
The flexural strength, flexural modulus and maximum shear stress can be calculated by following equations [10].

$$
\begin{gathered}
\sigma_{\text {bend }}=\frac{3 F L}{2 w h^{2}} \\
\mathrm{E}_{\mathrm{f}}=\frac{F L^{3}}{4 \partial w h^{3}}=\frac{m L^{3}}{4 w h^{2}} \\
\tau_{\max }=\frac{3 F}{4 w h}
\end{gathered}
$$

Where:-

$\sigma_{\text {bend }}$ : Flexural strength $(\mathrm{MPa})$.

$\mathrm{E}_{\mathrm{f}}$ : Flexural modulus (Modulus of elasticity in blending) $(\mathrm{GPa})$.

$\tau_{\max }:$ Maximum shear stress $(\mathrm{MPa}),(\partial)$ : Is the deflection of the beam when a force $\mathrm{F}$ is applied, L: Is the distance between the two supported points $(\mathrm{m}), \mathrm{W}$ : Is the width of the specimen $(\mathrm{m}), \mathrm{H}$ : Is the thickness of the specimen $(\mathrm{m})$.

Impact test is performed according to ISO 179 [11], by using measurement test machines; XJU-22 Time group. Each sample was tested for 3 times and average results have been reported at room temperature

Impact strength: - can be calculated from the following relationship [12]:-

$$
\mathrm{G}_{\mathrm{c}}=\frac{\mathrm{U}_{\mathrm{c}}}{\mathrm{A}}
$$

Where:-

Gc: Is the impact strength of the material $\left(\mathrm{KJ} / \mathrm{m}^{2}\right)$, Uc: Is the required energy for sample fracture $(\mathrm{KJ}), \mathrm{A}$ : Is the cross section area of the sample $\left(\mathrm{m}^{2}\right)$.

Fracture toughness: - can be calculated as follows [12]:-

$$
\mathrm{K}_{\mathrm{c}}=\sqrt{\mathrm{G}_{\mathrm{c}} \mathrm{E}_{\mathrm{f}}}
$$

Where:-

$\mathrm{K}_{\mathrm{c}}$ : Is fracture toughness of the sample $(\mathrm{MPa} \sqrt{ } \mathrm{m}), \mathrm{G}_{\mathrm{c}}$ : Is impact strength of the material $\left(\mathrm{KJ} / \mathrm{m}^{2}\right), \mathrm{E}_{\mathrm{f}}$ Is flexural modulus $(\mathrm{GPa})$.

Hardness test carried out at room temperatureon a durometer D scaleASTM D 2240 specimen dimension $(10 \times$ $10 \times 4) \mathrm{mm}$ each sample was test for five time in different regions [13].

\section{Results and Discussion}

\subsection{Tensile Test}

Figure (1) shows the (stress-strain) curves with different ratios by increasing the weight percentage of PP (5\%, 10\%, $15 \%$ and $20 \%$ ). It was found from this figure behavior change from hard to soft when addition the PP to PS. As well as it was shown from these curves the samples in the begging of the load show the elastic behavior then the behavior change in to plastic deformation behavior until to fracture. Also from Figure (1) shows that sample of ratio (95\%PS: $5 \% \mathrm{PP}$ ) bear maximum stress at fracture and lower elongation as compared to polymer blends samples of other ratios. This ratio could bear stress $(37.5 \mathrm{MPa})$ with an elongation $(2.45 \%)$.

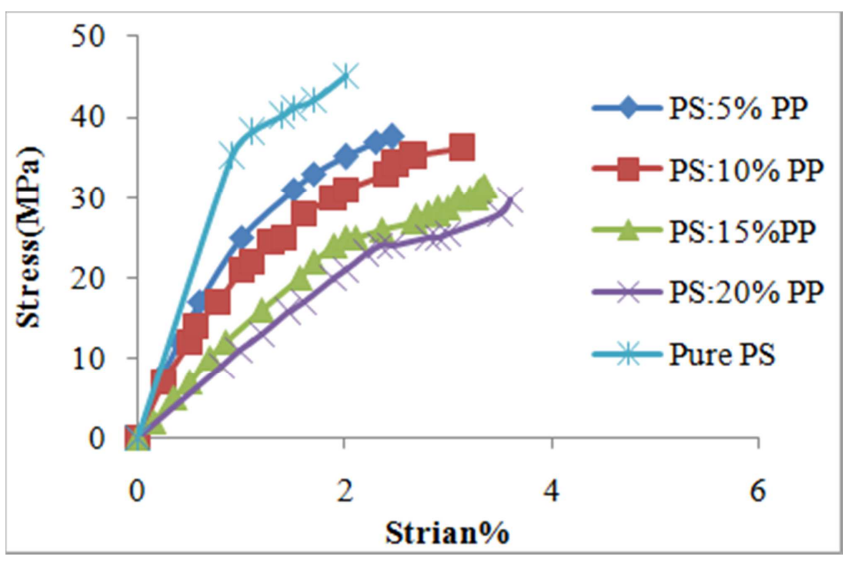

Fig. (1). Stress-strain curve of the polymer blend (PS: PP).

The fracture strength, young's modulus and elongation at break for samples of polymer blends are shown in Figures (2, 3 and 4) respectively. It was noticed from these figures that the samples of polymer blends (PS: PP) as compared with PS get lower values of fracture strength and the young's modulus but high elongation because PP has high strain to failure.

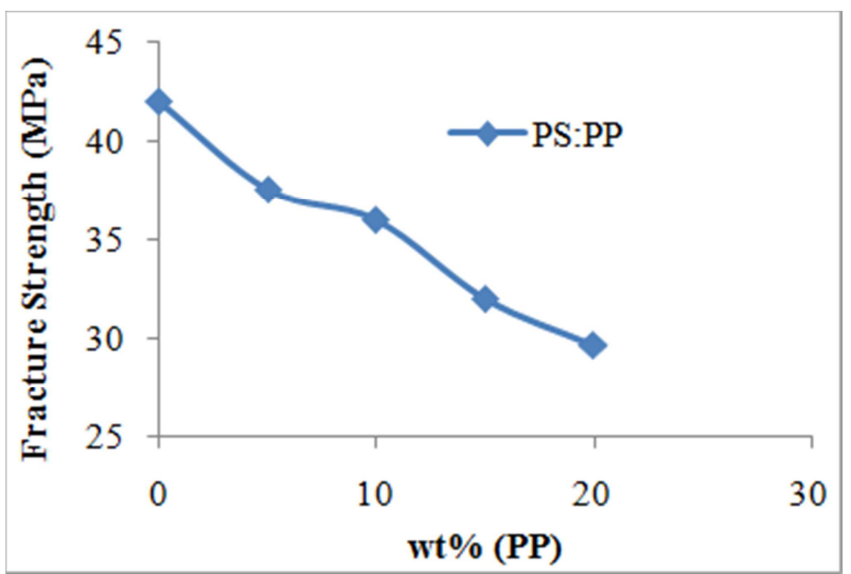

Fig. (2). Fracture strength for the polymers blends (PS: PP) as a function of $(P P)$ content in blend.

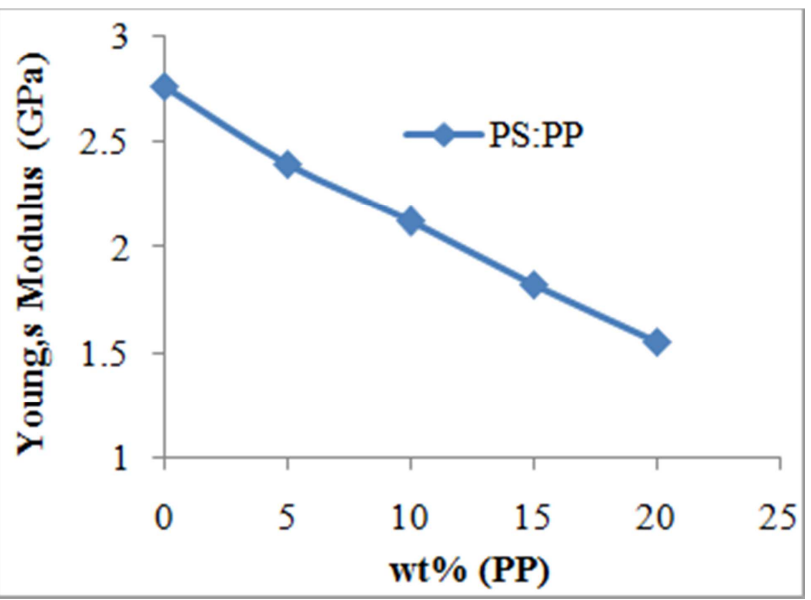

Fig. (3). Young's modulus for the polymers blends (PS: PP) as a function of (PP) content in blend. 


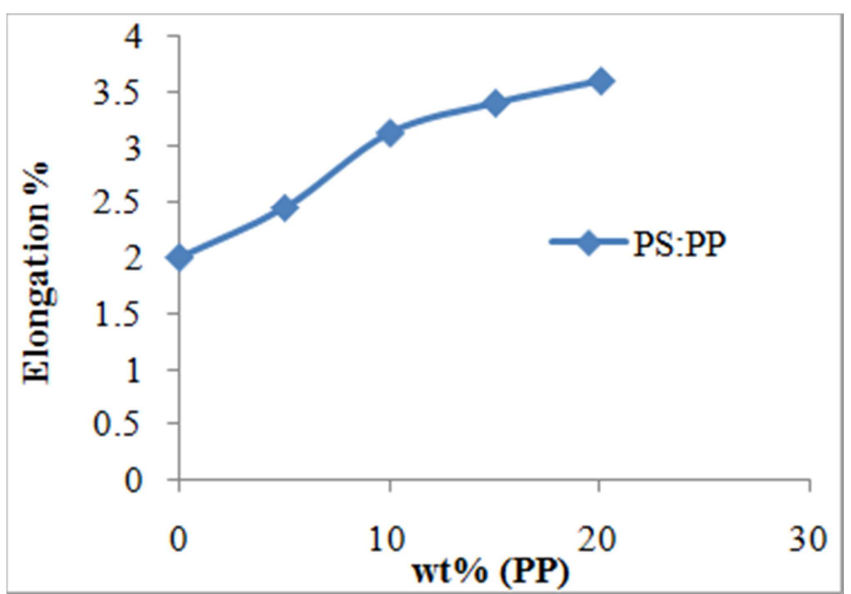

Fig. (4). Elongation percentage at break for the polymers blends (PS: PP) as a function of $(P P)$ content in blend.

the fracture strength and young's modulus values for samples decrease with increasing PP ratio in the blend content, while the elongation of these samples increase with increase PP content in the blend.

The above results refer to the nature of chain microstructure for polystyrene, the presence of the phenylene ring on every other carbon atom of the main chain of polystyrene produce a rigid bulky configuration with sufficient steric hindrance to make the polymer blends very inflexible [14].

The effect of addition ABS or EPDM with the ratios of $(1 \%, 3 \%$ and $5 \%)$ to the polymers blends (PS: $5 \% \mathrm{PP})$ on the behavior of (stress-stain) curves are shown in Figures ( 5 and 6) respectively. From these figures it was found the increases the weight percentage of ABS or EPDM decreased the value of fracture strength and increasing the elongation all samples of polymer blend.

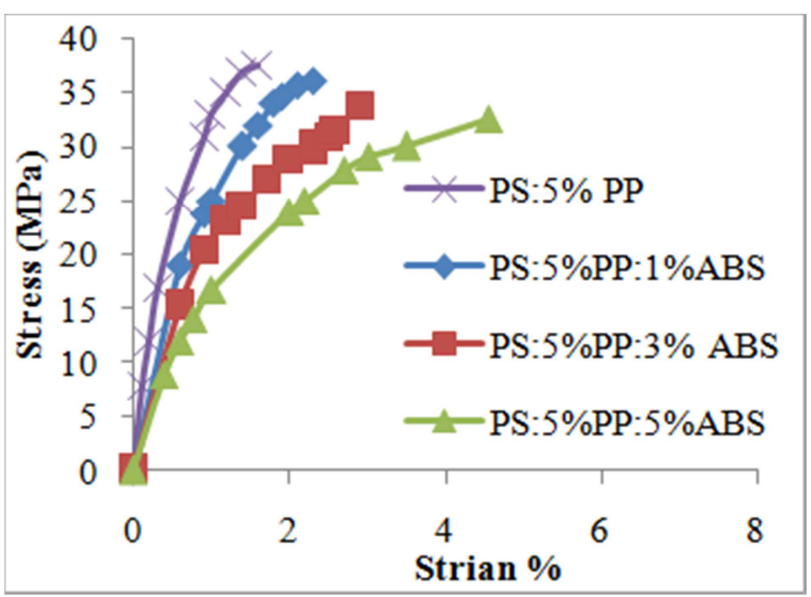

Fig. (5). Stress-strain curve for the polymer blend (PS: 5\%PP:ABS).

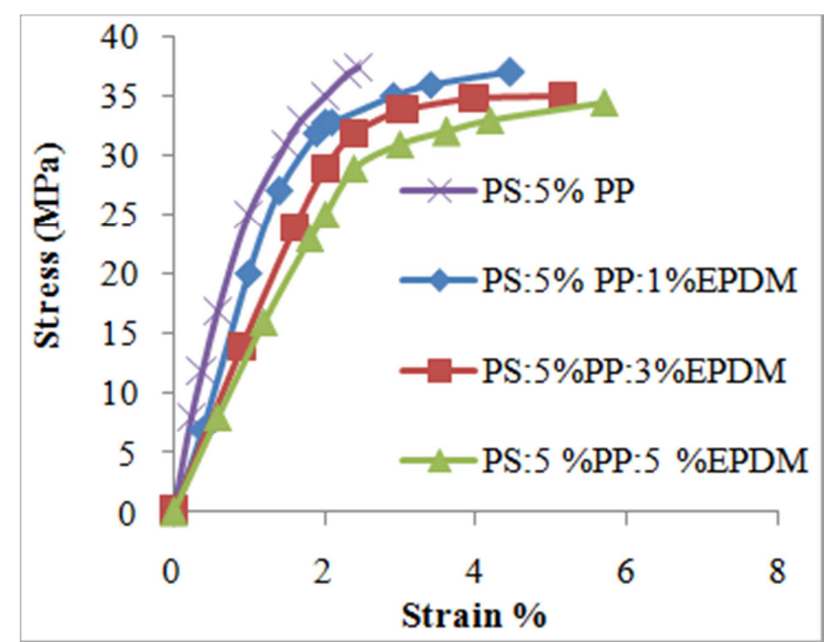

Fig. (6). Stress-strain curve for the polymer blend (PS: 5\%PP: EPDM).

Figures (7, $8 \& 9)$ have shown the comparison of tensile properties fracture strength, young's modulus and elongation percentage at break for the base polymers blends (PS:5\%PP) after addition ABS or EPDM to the blends. From these figures it was found that the addition EPDM or ABS to the base polymer blends decrease fracture strength and young's modulus, whereas the elongation at break increase with addition ABS or EPDM to these polymers blends. As well as from these figures it was observed that the polymer blends (PS: 5\%PP: EPDM) get the higher values of fracture strength and elongation at break Figure ( 8 \& 9), whereas lower values in young's modulus Figure (8). The sample with ratio (94\%PS: 5\%PP: 1\%EPDM) have maximum stress at fracture and less elongation as compared to samples of other ratios. This polymer blend ratio could bear stress (37MPa) with an elongation (4.466\%) as compared with counter parts of other groups sample of polymer blends (PS:5\%PP:ABS). On the other hand, samples of other ratios bear low stresses but high elongation.

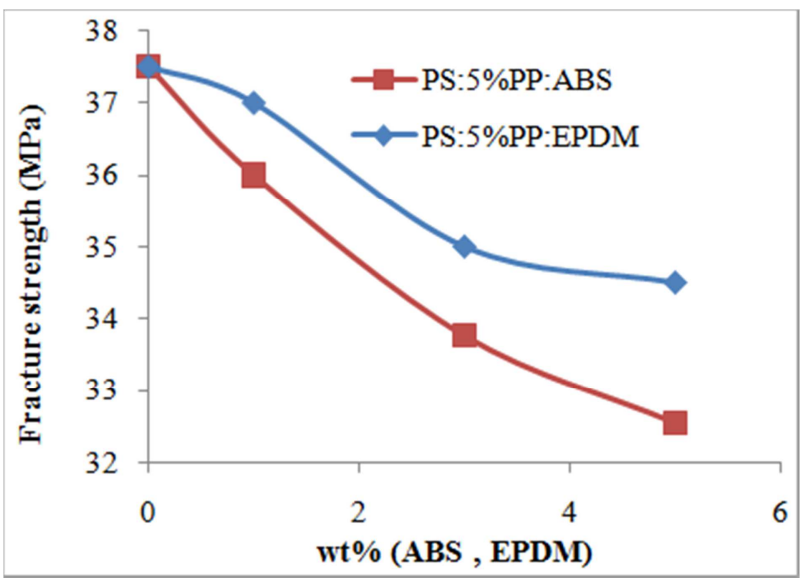

Fig. (7). Comparing fracture strength between the two groups of the main polymers blends after addition of ABS or EPDM to it. 


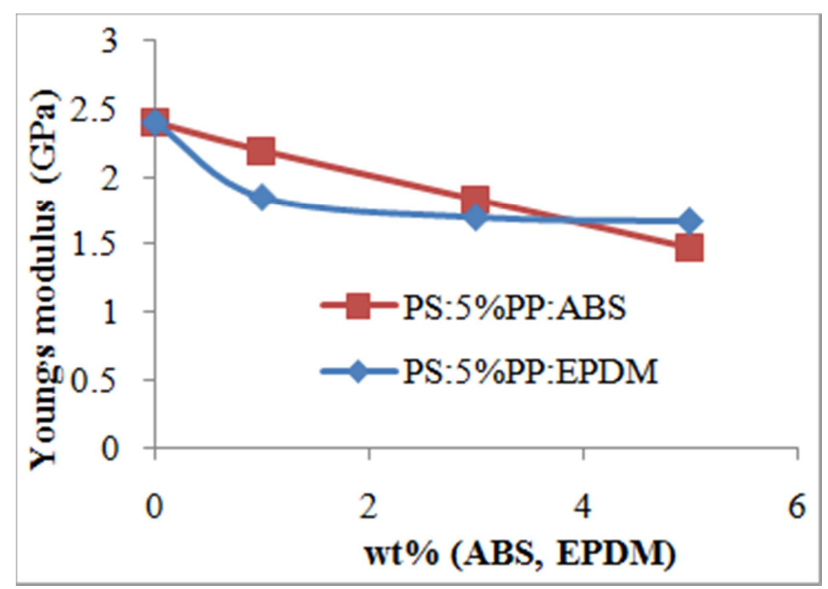

Fig. (8). Comparing young's modulus between the two groups of the main polymers blends after addition of ABS or EPDM to it.

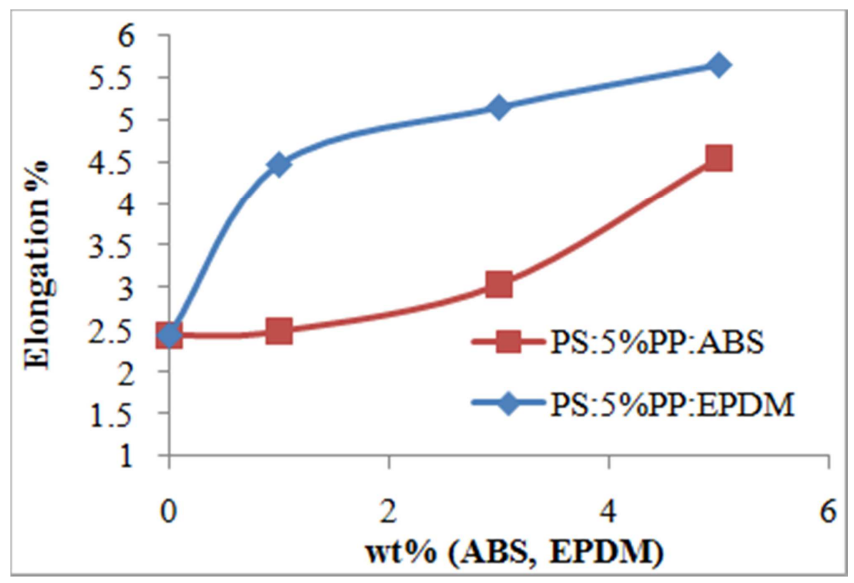

Fig. (9). Comparing elongation at break between the two groups of the main polymers blends after addition of ABS or EPDM to it.

\subsection{Flexural Strength Test}

From Figures $(10,11$ and 12) it was noticed that decrease the flexural strength $\left(\sigma_{\text {bend. }}\right)$, flexural modulus $\left(E_{f}\right)$ and maximum shear stress $\left(\tau_{\max }\right)$ respectively for polymer blends (PS: PP) with increase contain of (PP) in polymer blends which is related to structure of PP, PP is a semi-crystalline and ductile polymer belongs to aliphatic group with straight carbon chains.

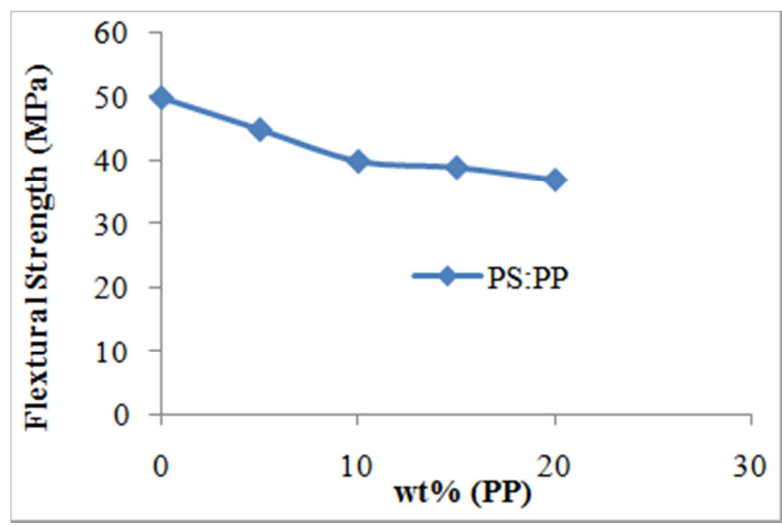

Fig. (10). Flexural strength for the polymer blends (PS: PP) as a function of (PP) content in blend.

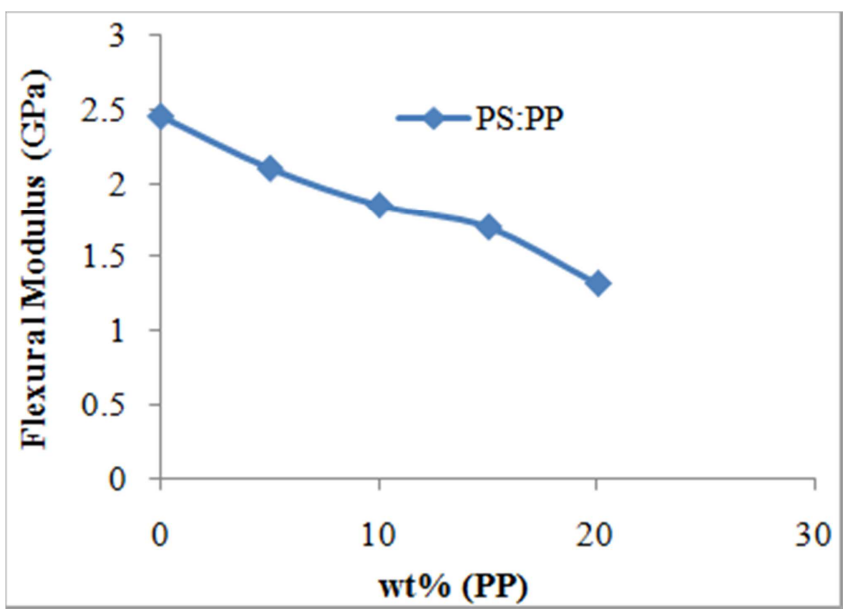

Fig. (11). Flexural modulus for the polymer blends (PS: PP) as a function of (PP) content in blend.

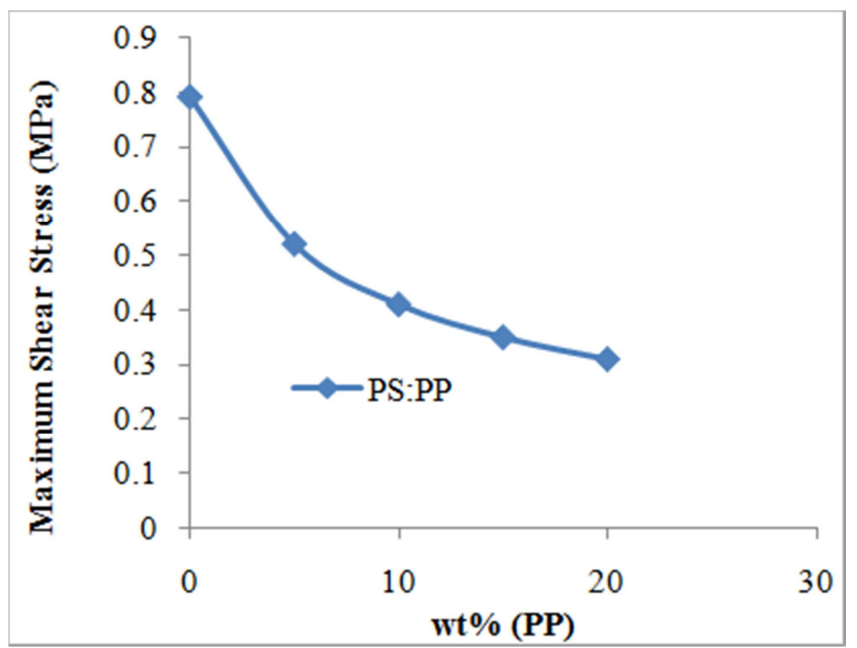

Fig. (12). Maximum shear stress for the polymers blends (PS:PP) as a function of $(P P)$ content in blend.

Figures $(13,14 \& 15)$ show the flexural strength, flexural modulus and maximum shear stress of the best main polymer blend (PS: $5 \% \mathrm{PP}$ ) after addition of $\mathrm{ABS}$ or $\mathrm{EPDM}$ ), from these figures it was noticed that the additions of ABS or EPDM to these polymer blends decrease the flexural strength, flexural modulus and maximum shear stress, the above results is due to the nature of chemical structure of each of the ABS and EPDM, the nature chemical structure of copolymer blend ABS which is a terpolymer prepared from the combination of a acrylonitrile, butadiene and styrene monomers, so the wide range of engineering properties of $\mathrm{ABS}$ is due to the contributing properties of each of its components. Acrylonitrile contributes toughness, butadiene provides impact strength, and styrene provides surface gloss and rigidity. Whereas the nature of chemical structure of EPDM terpolymer as copolymer made from three monomer is ethylene, propylene and diene monomer rubber. As well as the nature of interaction between polymer blend components and ABS or EPDM which acts as an agent to increase the interfacial reaction and provides an effective compatibility and good adhesion between the interface of all constituent of polymer blend [15 and 16]. 


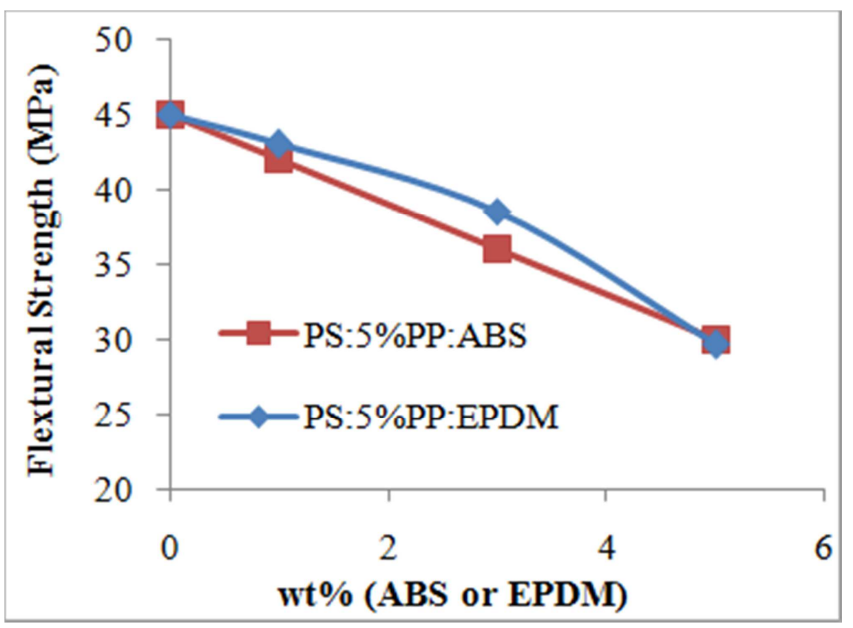

Fig. (13). Comparing flexural strength between the two groups of the main polymers blend (PS: $5 \% P P$ ) after addition of ABS or EPDM to it.

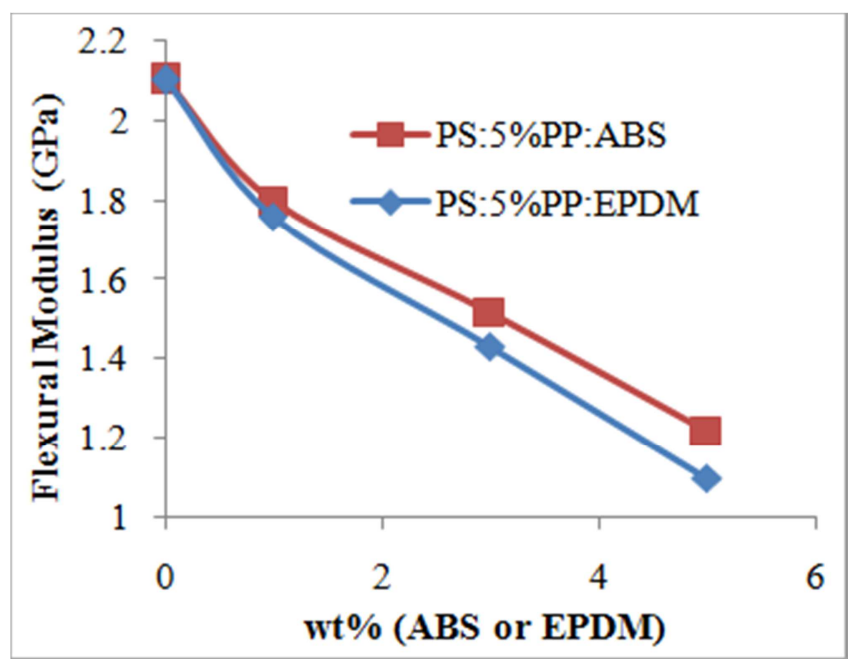

Fig. (14). Comparing flexural modulus between the two groups of the main polymers (PS: $5 \%$ PP) blend after addition of ABS or EPDM to it.

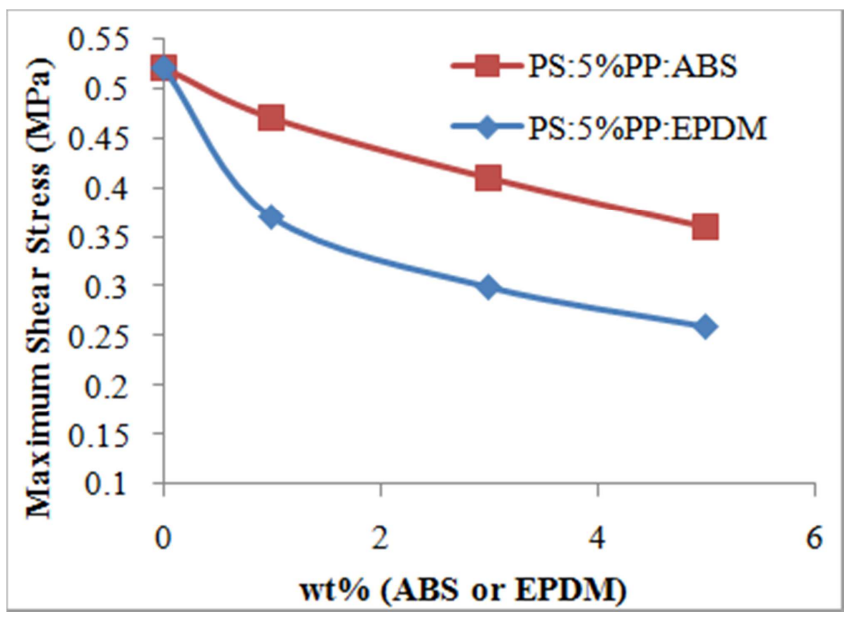

Fig. (15). Comparing maximum shear stress between the two groups of the main polymers blend (PS: $5 \%$ PP) after addition of ABS or EPDM to it.

\subsection{Impact test}

From Figures (16 \& 17) it was noticed that the impact strength and fracture toughness of the base polymers blends
(PS: PP) increase with increase (PP) contain in blends.

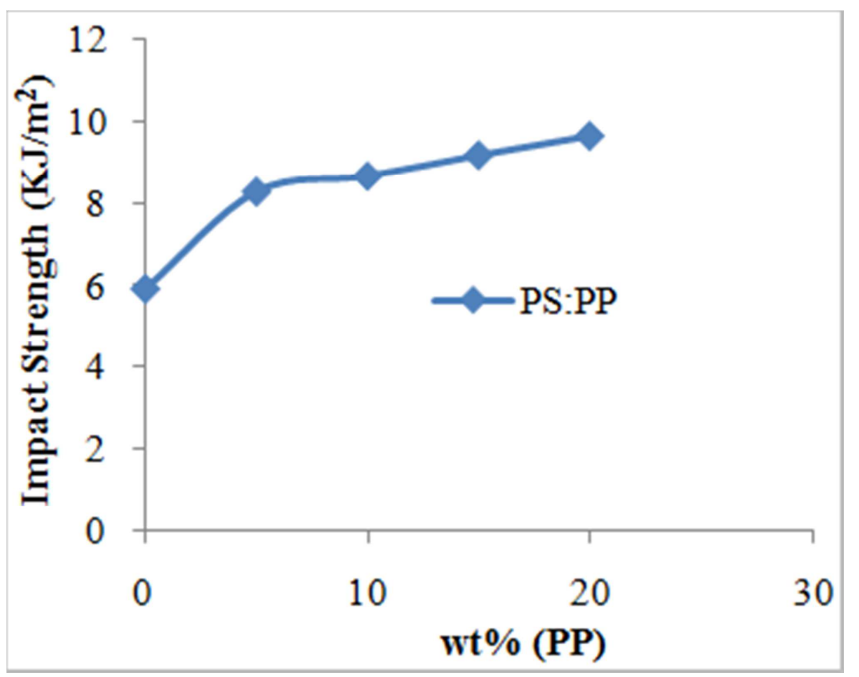

Fig. (16). Impact strength for the polymers blends (PS: PP) as a function of (PP) content in blend.

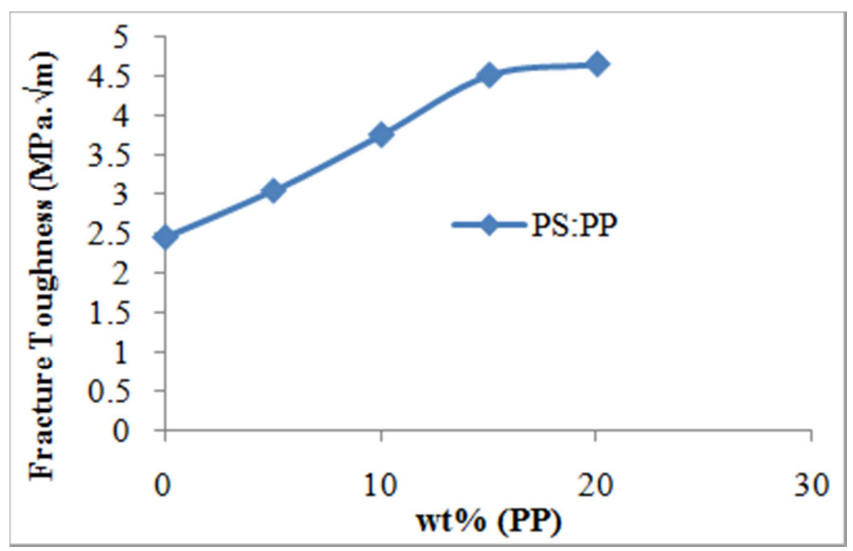

Fig. (17). Fracture toughness for the polymers blends (PS: PP) as a function of $(P P)$ content in blend.

The impact toughness is often the deciding factor in material selection because impact test measures the ability of polymer to withstand the load imposed upon being struck by an object at high velocity, thus it is a measure of energy required to propagate a crack across the specimen; therefore the impact properties of these samples are especially important.

The addition of (1, 3 and $5 \mathrm{wt} \%)$. (ABS) and (EPDM) raised the value of impact strength and fracture toughness for the base polymers blend (PS: $5 \% \mathrm{PP}$ ), it is possible to notice that from Figures $(18 \& 19)$ respectively. As well as it was notice from Figure (18) that the polymer blends (PS:5\%PP:EPDM) got the higher values of impact strength as compared with their counter part of the other group samples of polymer blends (PS:5\%PP:ABS). Whereas the addition of ABS to the polymer blends (PS:5\%PP) Figure (19) make the fracture toughness of polymer blend (PS:5\%PP:ABS) gain the higher values as compared with their counter part of the other group samples of polymer blends (P:S:5\%PP:EPDM). 


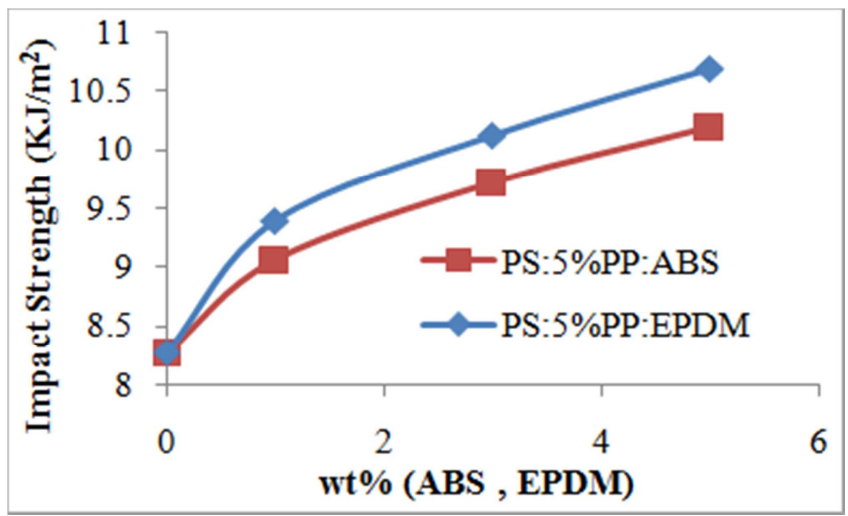

Fig. (18). Effect of addition ABS or EPDM on the impact strength of polymer blend (PS: 5\%PP).

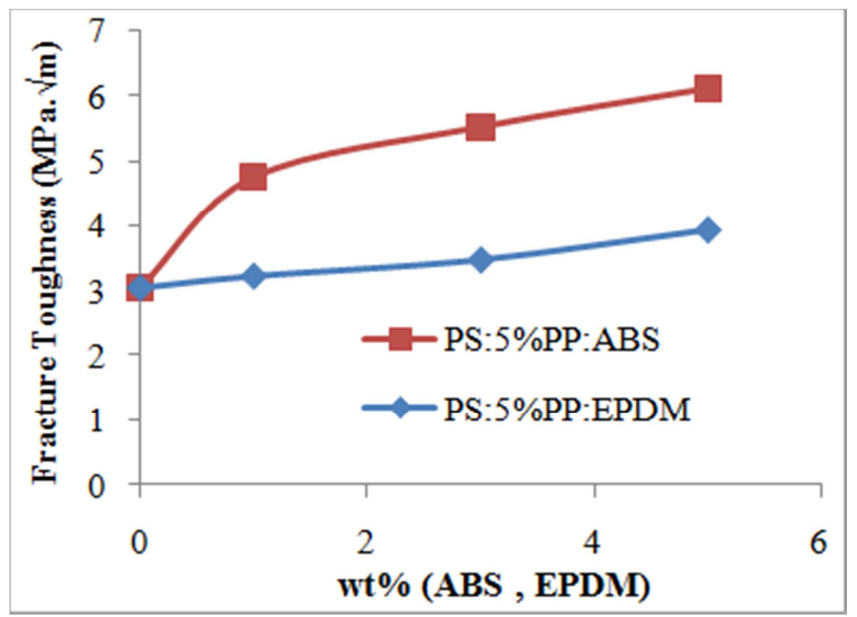

Fig. (19). Effect of addition ABS or EPDM on the fracture toughness of polymer blend (PS: $5 \%$ PP).

\subsection{Hardness Test}

Hardness (Shore D) was taken for the base polymers blends (PS: PP), the results are shown in Figure (20) it was noticed from this figure that the hardness values for the polymer blend (PS: PP) was decreased with the addition of $\mathrm{PP}$ to the polymer blends content.

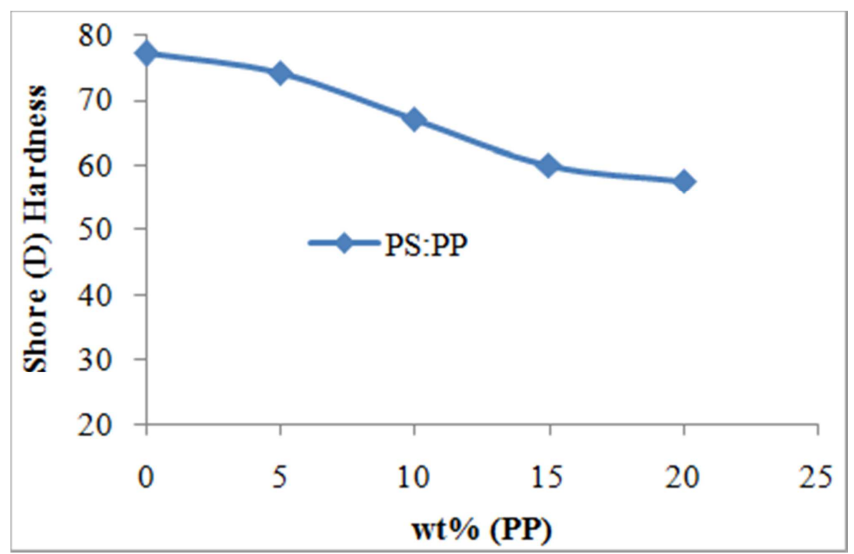

Fig. (20). Shore (D) Hardness for the polymers blends (PS: PP) as a function of PP additions to the blend.

The effect of addition ABS and EPDM on the hardness values of the best polymer blends (PS: 5\%PP) have shown in Figures (21). It was observed from this figure that the addition of EPDM decreased the hardness values of these polymers blends but accrue slightly decrease when adding ABS.

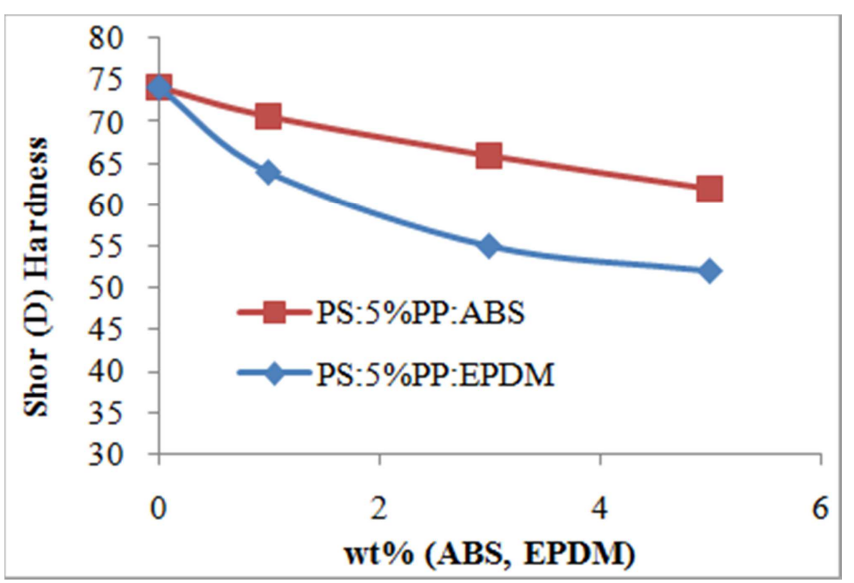

Fig. (21). Comparing shore (D) hardness after addition of ABS or EPDM to the polymers blend (PS: $5 \% P P)$.

\section{Conclusion}

1. The fracture strength, young's modulus, flexural strength, flexible modulus, maximum shear stress and hardness values of the matrix (pure PS) are higher than polymer blends (PS: PP).

2. The results, of the mechanical properties (fracture strength, young's modulus, flexural strength, flexible modulus, maximum shear stress and hardness) for the polymer blends (PS: PP) groups are decreases with increase PP content in polymer blends. The impact strength and elongation percentage increase when increase PP content in polymer blends.

3. The second stage is concerned with effect of addition of ABS or EPDM to the main polymer blends $(95 \% \mathrm{PS}$ : $5 \% \mathrm{PP})$, the result show the mechanical properties (tensile strength, flexural strength, hardness) are decrease with increase ABS and EPDM content in polymer blends expect the elongation and impact strength increase with increase ABS or EPDM content in polymer blends.

4. The maximum values of impact strength were $(10.68$ $\left.\mathrm{KJ} / \mathrm{m}^{2}\right)$ happened for $(90 \% \mathrm{PS}: 5 \% \mathrm{PP}: 5 \% \mathrm{EPDM})$ and the maximum values of fracture toughness were $(6.125$ $\mathrm{MPa} \sqrt{\mathrm{m}}$ ).for polymer blend (90\%PS: 5\%PP: 5\%ABS).

\section{References}

[1] V. Mittal, "Functional polymer blends: synthesis, properties, and performance ", international standerd book number: 9781-4398-5669-7, (2012).

[2] S. C. Siong, "Eeffects of polystyrene-modified natural rubber on the properties of polypropylene / polystyrene blends", University Sains Malaysia, Thesis of Master of Science, (2008). 
[3] A. A. Adewole, A. Denicola, C. G. Gogos and L. Mascia ," Compatibilization of polypropylene-polystyrene blends: Part 2, crystallization behavior and mechanical properties", Inc. Adv. Polym. Techn., Vol. (19): pp. 180-193, (2000).

[4] C.Jiang You and D.MinJia, "Effect of StyreneEthylene/PropleneDiblock Copolymer (SEP) on the Compatiblization of PP/PS Blends", Chinese Journal of Polymer Science, Vol. (21), No.4, pp. 443-446, (2003).

[5] W. Viratyaporn, R. L. Lehman, and J. Joshi, "Impact resistance of selected immiscible polymer blends ", Society of Plastics Engineers [SPE] Annual Technical Conference Proceedings Cincinnati, (2007).

[6] W. Brostow, T. H. Grguric, O. O. Mejia, D. Pietkiewicz and V. Rek," Polypropylene + Polystyrene Blends with a Compatibilizer", ISSN 1618-7229, e-Polymers, no. 03, (2008).

[7] B.A. Ibrahim \& K.M. Kadum, " Influence of Polymer Blending on Mechanical and Thermal Properties", University of Technology, Vol. (4), No. 9, (2010).

[8] "Standard Test Method for Tensile Properties of Plastics D638M- 87b", Annual Book of ASTM Standard, Vol. 09.01, (1988).

[9] "Standard Test Methods for Flexural Properties of Unreinforced and Reinforced Plastics D 790- 86", Annual Book of ASTM Standard, Vol. 10.01 (1986).
[10] A. S. Brent, "Plastics Materials and processing ", $2^{\text {nd }}$ ed., Prentice Hall, (2000).

[11] Standard Test Method for Un-notched Cantilever Beam Impact Resistance of Plastics ASTM D 4812", Gmtc India MATerials Test Lab, (2014).

[12] N. N. B. Mohammad and A. Arsad, "Mechanical, Thermal and Morphological Study of Kenaf Fiber Reinforced rPET/ABS Composites", Malaysian Polymer Journal, Vol. 8, No. 1, pp. 813, (2013).

[13] "Standard Test Method for Plastics Properties- Durometer Hardness D 2240", Annual Book of ASTM Standard, Vol. 09.01, (1988).

[14] R.O. Ebewele, "Polymer Science and Technology", Boca Raton, New York,CRC Press, (2000).

[15] Sihama E. Salih, .Akram R. Jabur and Teeb A. Mohammed "The Effect of PVP Addition on the Mechanical Properties of [84\%LLDPE: $15 \%((\quad 100-\mathrm{X})$ \%PP: X\%PVP): 1\%Basalt Particle] Polymer Blend Composites" Eng. \& Tech. Journal, Vol.32, Part (A), No.3, PP 573-583 (2014).

[16] Sihama E. Salih, .Akram R. Jabur and Teeb A. Mohammed "Comparative Study of the Mechanical Properties of Two Groups Ternary Polymer Blends Composites" Eng. \& Tech. Journal, Vol.32, Part (A), No.7, PP 1870-1886 (2014). 